\title{
Toll-like receptor 4 is expressed with enteroviral replication in myocardium from patients with dilated cardiomyopathy
}

\author{
Mamoru Satoh, Motoyuki Nakamura, Tomonari Akatsu, Yudai Shimoda, Ikuo Segawa \\ and Katsuhiko Hiramori
}

Second Department of Internal Medicine, Iwate Medical University School of Medicine, Iwate, Japan

\begin{abstract}
Expressions of innate immune response proteins, most notably proinflammatory cytokines, against enteroviral (EV) infection have been documented in the heart of human dilated cardiomyopathy (DCM). Toll-like receptor 4 (TLR4) activates signaling pathways leading to the expression of proinflammatory cytokines implicated the etiology of DCM. We sought to determine whether EV replication activates TLR4-dependent immune response in myocardium obtained from patients with DCM. Endomyocardial biopsy tissues were obtained from 56 patients with DCM and 10 controls. Levels of plus- and minus-strand EV RNA and TLR4 mRNA were measured by real-time RT-PCR. Immunohistochemical analysis was performed to identify the cellular source of EV capsid protein VP1 and TLR4. Both plus- and minus-strand EV RNA were detected in 19 DCM patients (34\%). Neither strand of EV RNA was detected in controls. TLR4 mRNA levels were higher in DCM patients than in controls $(P<0.001)$. A positive correlation was found between TLR4 levels and each strand type of EV RNA in EV RNApositive patients (plus-strand vs TLR4: $r=0.69, P<0.001$; minus-strand vs TLR4: $r=0.65, P=0.002$ ). VP1/TLR4 double staining showed extensive colocalization of VP1 and TLR4 proteins in cytoplasm of cardiac myocytes in myocardium obtained from DCM patients. EV RNA-positive patients showed lower systolic function and larger ventricular volume compared with EV RNA-negative patients left ventricular ejection fraction (LVEF): $P=0.002$; left ventricular end-systolic diameter (LVESD): $P=0.004)$. The DCM subgroup with high TLR4 levels showed lower LVEF and larger LVESD than the subgroup with TLR4 levels (both $P<0.001$ ). This study suggests that myocardial expression of TLR4 associates with EV replication in human DCM. EV RNA and TLR4 mRNA levels may correlate with LV dysfunction in DCM. The expression of TLR4 against EV replication may be involved in the pathogenesis of DCM.

Laboratory Investigation (2004) 84, 173-181, advance online publication, 15 December 2003; doi:10.1038/labinvest.3700031
\end{abstract}

Keywords: cytokines; immunology; infection/inflammation; signal transduction; viral diseases

Enteroviral (EV) RNA has been detected in a proportion of patients with dilated cardiomyopathy (DCM). ${ }^{1,2}$ It has been demonstrated that the detection of EV RNA in myocardium of DCM patients is associated with adverse prognosis. ${ }^{3}$ In particular, the presence of minus-strand EV RNA indicates active viral replication, and plays a role in the development of myocardial injury in DCM. ${ }^{4}$ Our previous study has reported that myocardial expression levels of tumor necrosis factor- $\alpha(\mathrm{TNF}-\alpha)$ and $\mathrm{EV}$ RNA were increased in patients with DCM regardless of etiology of left ventricular (LV) dysfunction. .,6 $^{5}$ It is likely that an immune response against viral

Correspondence: M Satoh, Second Department of Internal Medicine, Iwate Medical University School of Medicine, Uchimaru 19-1, Morioka 020-8505, Iwate, Japan.

E-mail: m_satoh@imu.ncvc.go.jp

Received 11 July 2003; revised 14 October 2003; accepted 17 October 2003; published online 15 December 2003 pathogens is important in the pathogenesis of DCM. However, the precise mechanism underlying tissue injury in virus-mediated cardiomyopathy is not clear.

A family of toll-like receptors (TLRs) has recently been identified as a key component of pathogenassociated molecular pattern recognition machinery. ${ }^{7}$ At least nine types of human TLRs have recently been identified. ${ }^{7}$ It has been shown that active TLR4 led to expression of nuclear factor- $\kappa \mathrm{B}$ $(\mathrm{NF}-\kappa \mathrm{B})$-controlled genes for proinflammatory cytokines that are required for activation of the immune response. ${ }^{8}$ TLR4 may therefore be an important factor in the signaling pathway in the host immune system in response to infectious disease. It has recently been reported that activation of antiviral immune response via TLR4 is important in the pathogenesis of viral infection. ${ }^{9}$

The purpose of this study was to determine whether TLR4 was expressed with EV replication, 
and to analyze the relationship between levels of TLR4 expression and clinical severity of DCM.

\section{Materials and methods}

\section{Subjects}

Endomyocardial tissues were obtained from 56 patients with primary DCM by right ventricular endomyocardial biopsy (42 male and 14 female patients; mean age $50.3 \pm 2.2$ years). The clinical diagnosis of DCM was made according to the World Health Organization/International Society and Federation of Cardiology Task Force criteria. ${ }^{10}$ Echocardiography was used to determine left ventricular ejection fraction (LVEF) and diameter immediately before the biopsy.

Control myocardial tissue samples were obtained by endomyocardial biopsy from 10 subjects (seven male and three female subjects; mean age $44 \pm 12$ years) with suspected cardiac disorder on the basis of ECG abnormality and echocardiographic changes, such as a slight increase in wall thickness without LV dysfunction. The resulting pathology findings showed no evidence of myocardial disease and these subjects were designated as controls. This study protocol was approved by our hospital ethics committee, and written informed consent was obtained from all subjects.

As a positive control of RT-PCR for EV RNA detection, we used HeLa cells incubated with $10^{6}$ plaque-forming units coxsackievirus B3 (CVB3) (Nancy strain).

\section{Extraction of RNA}

Total RNA was extracted from endomyocardial tissues and positive control cells by the acid guanidinium thiocyanate-phenol-chloroform method, and treated with DNase I (GIBCO BRL). ${ }^{11}$

\section{Primers and TaqMan Probes}

Plus- and minus-strand EV RNAs were amplified by using two sets of primers and TaqMan probes that recognized the $5^{\prime}$ uncoding genomic region (forward primer: $5^{\prime}$ GGG CGC TAG CAC TCT GGT AT $3^{\prime}$, reverse primer: $5^{\prime}$ GCC GGA TAA CGA ACG CTT T $3^{\prime}$ and TaqMan probe: $5^{\prime}$ ATC AAG CAC TTC TGT TAC CCC GGA CTG A $3^{\prime}$ ). ${ }^{12}$ The published sequence for human TLR4 was used for construction of primers and TaqMan probe (forward primer: $5^{\prime}$ TGA TTG TTG TGG TGT CCC A $3^{\prime}$, reverse primer: $5^{\prime}$ TGT CCT CCC ACT CCA GGT AA $3^{\prime}$ and TaqMan probe: $5^{\prime}$ TCC TGC AGA AGG TGG AGA AGA CCC T $\left.3^{\prime}\right) .{ }^{8}$ For all myocardial specimens, glyceraldehyde-3-phosphate dehydrogenase (GAPDH) mRNA was amplified using TaqMan GAPDH control reagents as an internal control (PE Biosystem, Foster City, CA, USA).

\section{Real-time RT-PCR}

Total RNA of each biopsy was transcribed into cDNA of TLR4 and GAPDH by MultiScribe RT with random hexamers (TaqMan Gold RT-PCR kit, PE Biosystem). In separate experiments to determine the polarity of EV RNA, the cDNA of plus-strand EV RNA was synthesized in $10 \mu \mathrm{l}$ of solution containing $100 \mathrm{ng}$ total RNA, $10 \times$ TaqMan RT-buffer, $10 \mathrm{mM}$ deoxyNTPs mixture, $20 \mathrm{mM} \mathrm{EV}$ reverse primer and $1.25 \mathrm{IU}$ MultiScribe RT as described by the manufacturer. The cDNA of minus-strand EV RNA was synthesized in the same way using EV forward primer instead of EV reverse primer. The RT reaction was performed at $37^{\circ} \mathrm{C}$ for $30 \mathrm{~min}$, and heated at $95^{\circ} \mathrm{C}$ for $5 \mathrm{~min}$ to inactivate RT activity.

PCR mixture was added to each RT mixture containing $0.025 \mathrm{U}$ AmpliTaq Gold DNA polymerase, AmpErase UNG, $25 \mathrm{mM} \mathrm{MgCl}_{2}$, primer and TaqMan probe, and $10 \times$ TaqMan buffer A. Each of 40 reaction cycles consisted of denaturation for $15 \mathrm{~s}$ at $95^{\circ} \mathrm{C}$, and annealing and extension for $1 \mathrm{~min}$ at $60^{\circ} \mathrm{C}$. To improve the accuracy of real-time RT-PCR for quantification, amplifications were performed in triplicate for each RNA sample. To account for variations in input RNA and RT efficiency, EV RNA and TLR4 levels were normalized to GAPDH expression in each sample. To account for PCR amplification of contaminating genomic DNA, a control without RT was included.

\section{Immunohistochemistry}

EV capsid protein VP1/TLR4 double staining was performed on serial paraffin sections to determine the cellular source of EV capsid protein VP1 and TLR4. Monoclonal mouse anti-enterovirus against EV capsid protein VP1 (Dako, Glostrub, Denmark) and mouse monoclonal $\operatorname{IgG}_{2 \mathrm{a}}$ against human TLR4 (Santa Cruz Biotechnology) were used as primary antibodies. The tissue sections were deparaffined and thoroughly dehydrated. After inhibition of endogenous peroxidase and blocking of non specific reactions, mouse monoclonal $\operatorname{IgG}_{2 \mathrm{a}}$ against human TLR4 was applied. Biotinylated mouse immunoglobulin was used as a secondary antibody. Peroxidaselabeled streptavidin (Histofine, MAX-PO kit, Nichiren Corp) was applied and visualized using diaminobenzidine as a chromogen.

For double-staining, mouse monoclonal $\operatorname{IgG}_{2 \mathrm{a}}$ against human TLR4 was first stained as mentioned above. Thereafter, the sections were incubated with monoclonal mouse antienterovirus against EV capsid protein VP1 at $4^{\circ} \mathrm{C}$ overnight, followed by incubation for $30 \mathrm{~min}$ with rabbit anti-mouse immunoglobulin and alkaline phosphatase anti-alkaline phosphatase, and visualized with FastBlue (Histofine, SAP-AP kit, Nichiren Corp). The specificity of the immunohistochemistry was confirmed by substituting the primary antibodies with mouse 
IgG1 negative control (Dako) on control sections from patients with DCM.

\section{Statistical Analysis}

All values are presented as mean \pm s.e. Statistically, the differences in EV RNA and TLR4 expression levels between the DCM and control groups were analyzed by unpaired $t$ test. Pearson's correlation coefficients were used to examine the relationship between levels of mRNA expression and clinical parameters. A value of $P<0.05$ was considered statistically significant.

\section{Results}

\section{EV RNA and TLR4 mRNA Levels in Myocardial Tissues}

Plus- and minus-strand EV RNAs were detected in $19(34 \%)$ of the 56 patients with DCM (mean levels of plus-strand EV RNA/GAPDH ratio and minusstrand EV RNA/GAPDH ratio in EV RNA-positive patients with DCM: $1.63 \pm 0.37$ and $1.27 \pm 0.30$, respectively). All patients who were positive for minus-strand EV RNA were also positive for plusstrand EV RNA. A positive correlation was found between plus- and minus-strand EV RNA levels in EV RNA-positive patients with DCM $(r=0.90$, $P<0.001$ ) (Figure 1). Neither strand of EV RNA was detected in controls. In infected HeLa cells, the level of plus-strand EV RNA was higher than that of minus-strand EV RNA (plus-strand EV RNA/ GAPDH ratio: $24076.68 \pm 1830.32$, minus-strand EV RNA/GAPDH ratio: $285.61 \pm 14.15)$.

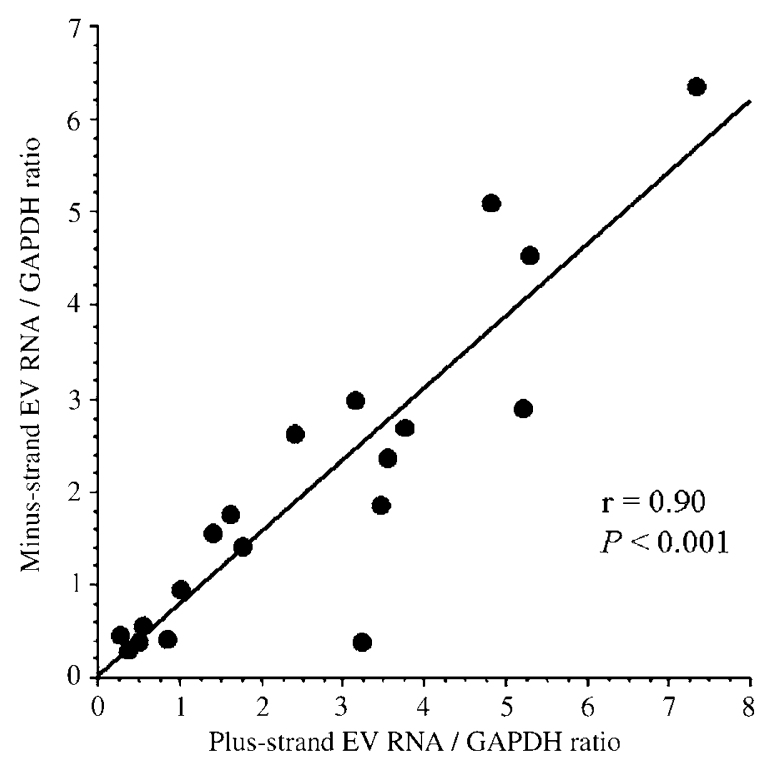

Figure 1 Correlation plot between plus- and minus-strand EV RNA levels in myocardium obtained from patients with DCM. Significant correlation: $r=0.90, P<0.001$.
TLR4 mRNA levels were higher in patients with DCM than in controls (TLR4/GAPDH ratio: $0.24 \pm 0.03$ vs $0.01 \pm 0.004, P<0.001)$. TLR4 mRNA levels were higher in EV RNA-positive DCM patients than in EV RNA-negative DCM patients (TLR4/GAPDH ratio: $0.38 \pm 0.06$ vs $0.16 \pm 0.03$, $P=0.001$ ) (Figure 2). A weak positive correlation was found between each strand of EV RNA and TLR4 mRNA levels in 19 EV RNA-positive patients with DCM (plus-strand EV RNA vs TLR4: $r=0.69$, $P<0.001$; minus-strand EV RNA vs TLR4: $r=0.65$, $P=0.002)$.

\section{Immunohistochemistry for TLR4 and EV Capsid Protein VP1}

EV capsid protein VP1 was detected in 17 of the 56 patients with DCM (30.3\%). As shown in Figure 3a, immunostaining of VP1 was observed in cytoplasm of cardiac myocytes in myocardium from patients with DCM. VP1 signals were found in scattered cardiac myocytes and myofibers in DCM. Both plusand minus-strand EV RNA were detected in all VP1positive patients with DCM. TLR4 immunostaining was positive in 35 patients with DCM (62.5\%). VP1/ TLR4 double staining showed extensive colocalization of VP1 and TLR4 proteins in cytoplasm of cardiac myocytes in myocardium obtained from DCM patients (Figure 3a). TLR4 mRNA levels were

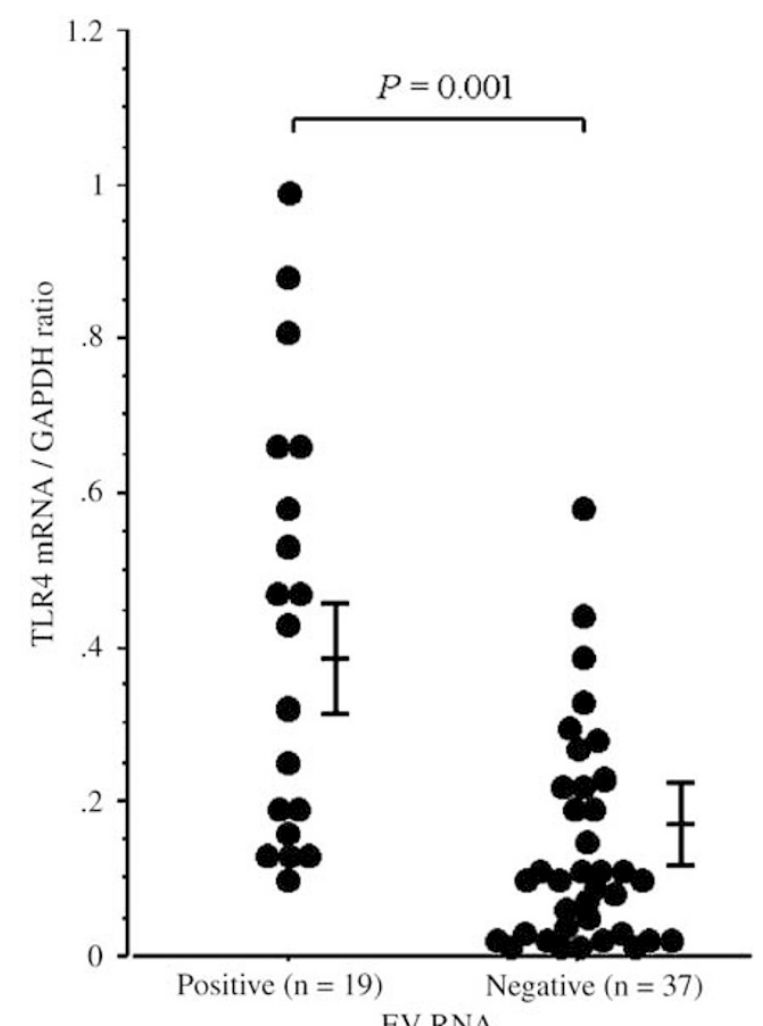

EV RNA

Figure 2 Comparison of TLR4 mRNA levels between EV RNApositive DCM patients and-negative DCM patients. 


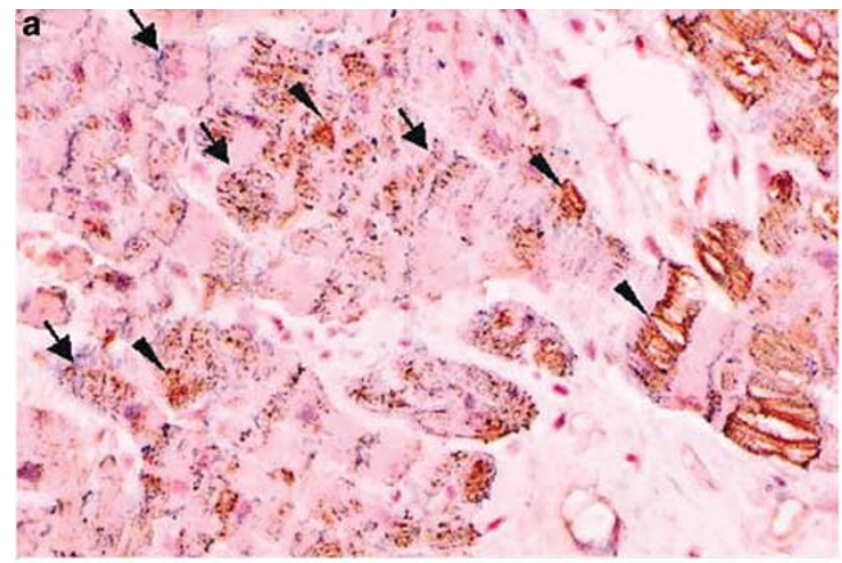

b

Figure 3 EV capsid protein VP1/TLR4 double staining of serial sections of myocardial tissue obtained from patients with DCM and controls. (a) Immunostainings of EV capsid protein VP1 (arrow, blue coloring) and TLR4 (arrow head, brown coloring) were positive in cardiac myocytes in biopsy samples obtained from DCM patients. VP1/TLR4 double staining showed colocalization of VP1 and TLR4 proteins in cardiac myocytes. (b) Immunostainings of VP1 and TLR4 in myocardial tissue obtained from control subjects. Neither VP1 nor TLR4 immunostaining was present in any specimens. Magnification: $\times 250$.

higher in DCM patients with TLR4 immunostaining than in those without TLR4 immunostaining (TLR4/ GAPDH ratio: $0.33 \pm 0.04$ vs $0.06 \pm 0.02, P<0.001$ ). TLR4 immunostaining was also positive in all EV capsid protein VP1-positive patients with DCM. There was no evidence of nonspecific immunostaining in myocardial tissues obtained from patients with DCM. Neither VP1 nor TLR4 immunostaining was present in any specimens from control subjects (Figure 3b).

\section{Clinical Outcome}

Table 1 summarizes results of RT-PCR and immunohistochemistry, and clinical outcomes in DCM patients. EV RNA-positive patients with DCM $(n=19)$ showed significantly lower LVEF compared with EV RNA-negative patients with DCM $(n=37)$ $(27.3 \pm 1.2 \%$ vs $34.6 \pm 1.5 \%, P=0.002)$ (Figure $4 \mathrm{a})$.
LV end-systolic diameter (LVESD) was larger in EV RNA-positive patients than in EV RNA-negative patients $(54.4 \pm 1.4 \mathrm{~mm}$ vs $50.3 \pm 0.6 \mathrm{~mm}, P=0.004)$ (Figure 4b). There was weak negative correlation between plus-strand EV RNA levels and LVEF in EV RNA-positive patients with DCM $(r=-0.52$, $P=0.02$ ). Both plus- and minus-strand EV RNA levels were also correlated positively with LVESD in EV RNA-positive patients with DCM (plus-strand EV RNA vs LVESD: $r=0.68, P=0.001$; minus-strand EV RNA vs LVESD: $r=0.59, P=0.007$ ).

We examined the differences in LVEF and LVESD between two groups with DCM divided relative to the mean TLR4 mRNA/GAPDH ratio $(=0.24)$. The group with high TLR4 $(\geq 0.24)$ showed lower LVEF and larger LVESD than the group with low TLR4 $(<0.24)$ (LVEF: $24.6 \pm 1.3$ vs $36.1 \pm 1.2 \%, P<0.001$; LVESD: $\quad 56.7 \pm 1.1 \quad$ VS $\quad 49.1 \pm 0.5 \mathrm{~mm}, \quad P<0.001)$ (Figure 5). TLR4 mRNA levels were negatively and weakly positively correlated with LVEF and LVESD respectively (TLR4 mRNA vs LVEF: $r=-0.72, \quad P<0.001 ; \quad$ TLR4 mRNA vs LVESD: $r=0.69, P<0.001)$.

\section{Discussion}

The most important finding of the present study is high levels of TLR4 mRNA and EV RNA in myocardium obtained from DCM patient with advanced LV dysfunction. Both strand types of EV RNA were positive in DCM patients, suggesting the possibility of EV replication in myocardium. Furthermore, there was a positive correlation between TLR4 mRNA and EV RNA levels in DCM patients. Both VP1 and TLR4 immunostaining were seen in scattered cardiac myocytes in DCM. These data therefore support a link between the toll signaling pathway and EV replication in human DCM.

Transcription of minus-strand RNA from the plusstrand EV genomic template is the essential first step of EV replication. This minus-strand RNA is then used as a template to generate multiple copies of plus-strand genomes that are translated into EV structural proteins and ultimately packed into new virions. ${ }^{13}$ Therefore, detection of minus-strand EV RNA is an indicator of active EV replication. In this study, minus-strand EV RNA was detected in all plus-strand-positive DCM patients. These findings indicate that active EV replication occurs in the myocardium in a significant proportion of cases of DCM.

Levels of the two strand types of EV RNA were comparable (plus-strand: $1.63 \pm 0.37$, minus-strand: $1.27 \pm 0.30$ ), and were positively correlated in DCM patients. No report has yet shown myocardial genome levels of both-strand EV RNA in human DCM. In a mouse model with persistent coxsackievirus infection, actual levels of plus- and minusstrand EV RNA were nearly equal in persistence in 
Table 1 Levels of each-strand EV RNA and TLR4 mRNA, immunohistochemistry of EV capsid protein VP1 and TLR4, and clinical outcomes in DCM patients

\begin{tabular}{|c|c|c|c|c|c|c|c|c|c|}
\hline \multirow[t]{2}{*}{ Patient No. } & \multirow[t]{2}{*}{ Age (years) } & \multirow[t]{2}{*}{ Sex } & \multicolumn{3}{|c|}{ Levels of EV RNA and TLR4 mRNA } & \multicolumn{2}{|c|}{ Immunohistochemistry } & \multirow[t]{2}{*}{$L V E F(\%)$} & \multirow[t]{2}{*}{$\operatorname{LVESD}(\mathrm{mm})$} \\
\hline & & & Plus-strand & Minus-strand & TLR4 & $V P 1$ & TLR4 & & \\
\hline 1 & 40 & $\mathrm{M}$ & 3.22 & 0.40 & 0.16 & + & + & 22 & 48 \\
\hline 2 & 22 & $\mathrm{M}$ & 3.54 & 2.36 & 0.47 & + & + & 22 & 64 \\
\hline 3 & 56 & $\mathrm{M}$ & 5.21 & 2.89 & 0.66 & + & + & 24 & 55 \\
\hline 4 & 49 & $\mathrm{M}$ & 0.56 & 0.56 & 0.13 & - & + & 26 & 49 \\
\hline 5 & 68 & $\mathrm{M}$ & - & - & 0.06 & - & - & 35 & 49 \\
\hline 6 & 68 & $\mathrm{M}$ & 1.40 & 1.56 & 0.25 & + & + & 29 & 62 \\
\hline 7 & 52 & $\mathrm{M}$ & 3.15 & 2.98 & 0.32 & + & + & 30 & 56 \\
\hline 8 & 22 & $\mathrm{~F}$ & 0.51 & 0.39 & 0.47 & - & + & 25 & 51 \\
\hline 9 & 48 & M & 2.42 & 2.62 & 0.10 & + & + & 22 & 56 \\
\hline 10 & 70 & $\mathrm{M}$ & 3.48 & 1.86 & 0.81 & + & + & 22 & 54 \\
\hline 11 & 65 & $\mathrm{~F}$ & 3.75 & 2.68 & 0.43 & + & + & 28 & 57 \\
\hline 12 & 66 & $\mathrm{~F}$ & 7.34 & 6.34 & 0.58 & + & + & 22 & 56 \\
\hline 13 & 67 & $\mathrm{M}$ & 5.31 & 4.55 & 0.66 & + & + & 33 & 66 \\
\hline 14 & 65 & $\mathrm{M}$ & 1.77 & 1.42 & 0.53 & + & + & 27 & 50 \\
\hline 15 & 50 & $\mathrm{~F}$ & 0.36 & 0.29 & 0.13 & + & + & 38 & 52 \\
\hline 16 & 42 & $\mathrm{M}$ & 1.01 & 0.94 & 0.19 & + & + & 33 & 46 \\
\hline 17 & 39 & $\mathrm{M}$ & 4.82 & 5.09 & 0.88 & + & + & 20 & 64 \\
\hline 18 & 73 & $\mathrm{M}$ & 1.61 & 1.77 & 0.13 & + & + & 28 & 49 \\
\hline 19 & 38 & $\mathrm{~F}$ & 0.27 & 0.46 & 0.19 & + & + & 33 & 49 \\
\hline 20 & 66 & $\mathrm{M}$ & - & - & 0.08 & - & + & 39 & 50 \\
\hline 21 & 54 & $\mathrm{M}$ & - & - & 0.11 & - & + & 42 & 51 \\
\hline 22 & 15 & $\mathrm{M}$ & - & - & 0.10 & - & + & 45 & 46 \\
\hline 23 & 41 & $\mathrm{M}$ & - & - & 0.19 & - & - & 36 & 49 \\
\hline 24 & 65 & $\mathrm{M}$ & - & - & 0.11 & - & - & 43 & 48 \\
\hline 25 & 70 & $\mathrm{M}$ & - & - & 0.02 & - & - & 39 & 47 \\
\hline 26 & 42 & $\mathrm{~F}$ & - & - & 0.01 & - & - & 38 & 48 \\
\hline 27 & 65 & $\mathrm{M}$ & - & - & 0.02 & - & - & 44 & 48 \\
\hline 28 & 70 & $\mathrm{M}$ & - & - & 0.01 & - & - & 41 & 47 \\
\hline 29 & 16 & $\mathrm{M}$ & - & - & 0.02 & - & - & 39 & 48 \\
\hline 30 & 25 & $\mathrm{M}$ & - & - & 0.10 & - & + & 42 & 46 \\
\hline 31 & 28 & $\mathrm{M}$ & - & - & 0.11 & - & + & 38 & 47 \\
\hline 32 & 55 & $\mathrm{~F}$ & - & - & 0.07 & - & - & 45 & 49 \\
\hline 33 & 43 & $\mathrm{~F}$ & - & - & 0.01 & - & - & 46 & 47 \\
\hline 34 & 20 & $\mathrm{M}$ & - & - & 0.11 & - & + & 21 & 49 \\
\hline 35 & 28 & $\mathrm{M}$ & - & - & 0.27 & - & + & 27 & 54 \\
\hline 36 & 64 & $\mathrm{M}$ & - & - & 0.28 & - & + & 30 & 55 \\
\hline 37 & 66 & $\mathrm{M}$ & - & - & 0.33 & - & + & 32 & 59 \\
\hline 38 & 53 & $\mathrm{M}$ & - & - & 0.22 & - & + & 19 & 60 \\
\hline 39 & 48 & $\mathrm{~F}$ & - & - & 0.04 & - & - & 39 & 48 \\
\hline 40 & 49 & $\mathrm{M}$ & - & - & 0.05 & - & - & 37 & 49 \\
\hline 41 & 68 & $\mathrm{~F}$ & - & - & 0.02 & - & - & 38 & 51 \\
\hline 42 & 29 & $\mathrm{M}$ & - & - & 0.10 & - & - & 41 & 45 \\
\hline 43 & 73 & $\mathrm{M}$ & - & - & 0.19 & - & - & 44 & 45 \\
\hline 44 & 66 & $\mathrm{M}$ & - & - & 0.22 & - & - & 29 & 49 \\
\hline 45 & 62 & $\mathrm{~F}$ & - & - & 0.03 & - & - & 37 & 49 \\
\hline 46 & 31 & $\mathrm{~F}$ & - & - & 0.09 & - & - & 39 & 52 \\
\hline 47 & 44 & $\mathrm{M}$ & - & - & 0.44 & - & + & 18 & 55 \\
\hline 48 & 60 & $\mathrm{M}$ & - & - & 0.30 & - & + & 22 & 49 \\
\hline 49 & 50 & $\mathrm{M}$ & - & - & 0.23 & - & + & 24 & 50 \\
\hline 50 & 59 & $\mathrm{M}$ & - & - & 0.58 & - & + & 19 & 59 \\
\hline 51 & 53 & $\mathrm{M}$ & - & - & 0.15 & - & + & 29 & 49 \\
\hline 52 & 66 & $\mathrm{M}$ & - & - & 0.39 & - & + & 26 & 53 \\
\hline 53 & 35 & $\mathrm{M}$ & 0.85 & 0.42 & 0.99 & + & + & 11 & 59 \\
\hline 54 & 39 & $\mathrm{~F}$ & - & - & 0.01 & - & - & 36 & 52 \\
\hline 55 & 55 & $\mathrm{~F}$ & - & - & 0.02 & - & - & 44 & 50 \\
\hline 56 & 41 & $\mathrm{M}$ & - & - & 0.03 & - & - & 43 & 50 \\
\hline
\end{tabular}

EV=enteroviral; TLR4=Toll-like receptor 4; DCM=dilated cardiomyopathy; LVEF=left ventricular ejection fraction; LVESD=left ventricular endsystolic diameter; $\mathrm{M}=$ male; $\mathrm{F}$, female.

the infectious phase ( 1 month after infection). ${ }^{14}$ In human skeletal muscle, Cunningham et $a l^{15}$ have demonstrated a persistent EV infection of skeletal muscle in patients suffering from chronic fatigue syndrome. Wessely et $a l^{16}$ have demonstrated that EV viral genome alone, in the absence of infectious virus, can exert direct pathological effects on cultured cardiac myocytes. These observations 


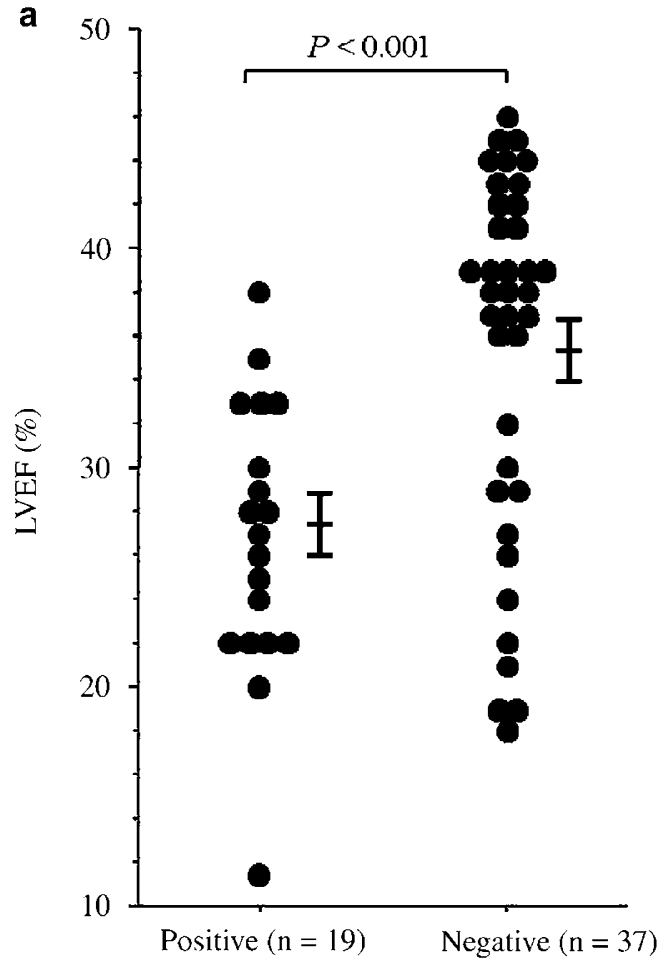

b

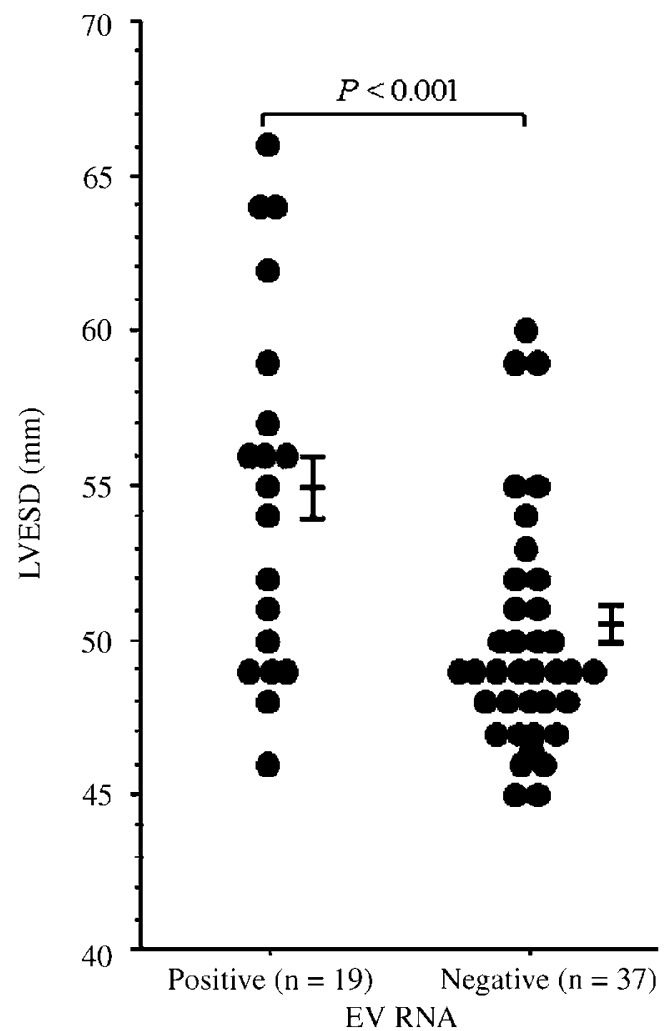

Figure 4 Comparison of LVEF (a) and LVESD (b) between EV RNA-positive DCM patients and EV RNA-negative DCM patients. $\mathrm{LVEF}=$ left ventricular ejection fraction; LVESD = left ventricular end-systolic diameter.

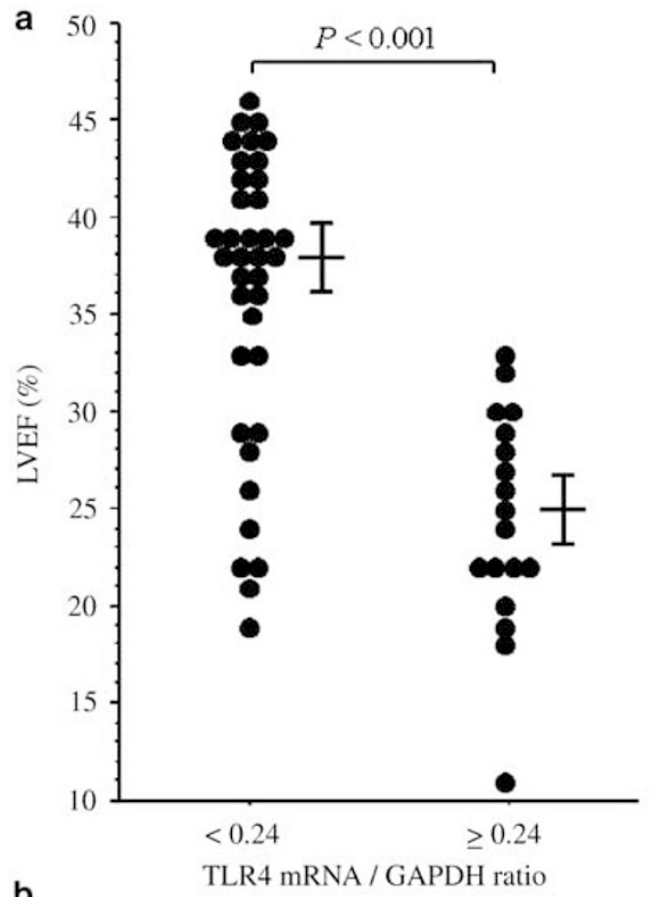

b

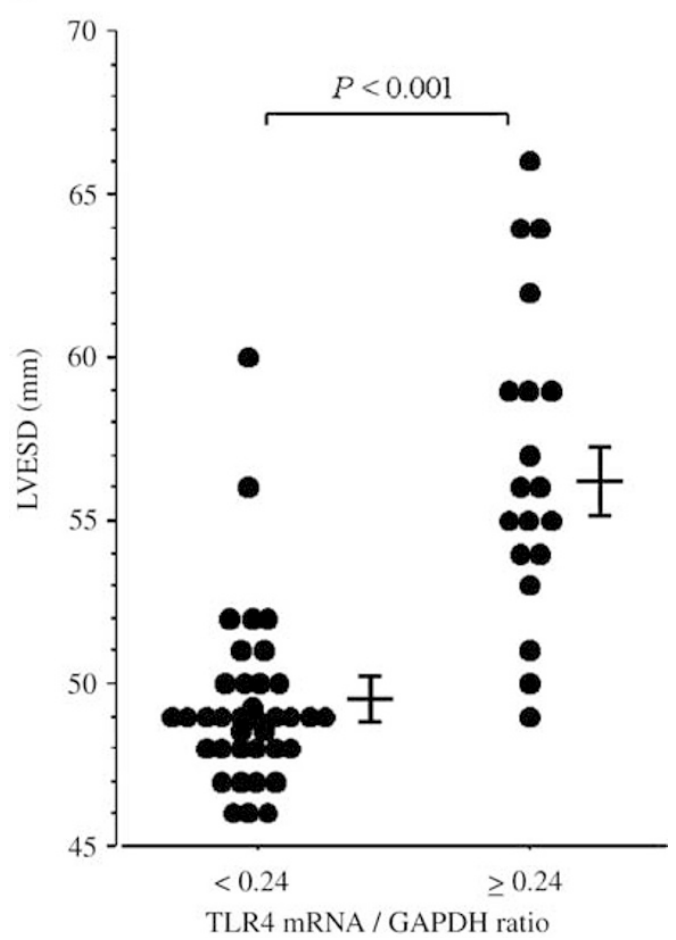

Figure 5 Comparison of LVEF and LVESD in two groups of patients with DCM divided by mean TLR4 mRNA expression levels.

suggest that plus-strand RNA synthesis could diminish as RNA polymerase activity subsides, leading to double-stranded EV RNA replication. EV RNA replication may therefore persist in myocardium in human DCM. The mechanism of equal synthesis of the two strands of EV RNA in these in vitro situations is unclear, but it is possible that downregulation of RNA polymerase activity occurs 
in infected myocardium through a host immune response.

This study has shown advanced LV dysfunction in EV RNA-positive patients with DCM compared to EV RNA-negative patients. There was a negative correlation between EV RNA levels and LVEF. Wessely et $a l^{17}$ have demonstrated that the transgenic expression of replication-restricted EV genome in the heart could induce LV dysfunction. In this model, defective-contraction coupling and a decrease in the magnitude of isolated myocyte shortening were observed. ${ }^{17}$ It has been reported that the presence of active EV replication can be a marker for poor outcome in patients with DCM. ${ }^{4}$ VP1 protein can be found in all DCM patients with both-strand EV RNA. These results suggest the possibility of viral protein synthesis in host cells during virus persistence. Li et $a l^{18}$ have demonstrated that the pattern of VP1 detection may correlate with disease stage and severity of DCM. Therefore, detection of VP1 protein and both plusand minus-strand EV RNA may indicate the persistence of infection in the heart, and may facilitate LV dysfunction in DCM.

At least two TLRs, including TLR2 and TLR4, have recently been implicated in lipopolysaccharide (LPS)-induced signal transduction. ${ }^{7,8}$ Although TLR2 expression is essential for responses to Gram-positive bacteria, mycobacteria and spirochetes, it is not required for responses to viral protein. ${ }^{19-21}$ The activation of TLR4 induces a variety of cytokines and costimulatory molecules that are crucial to immune responses. ${ }^{8}$ Recent study has reported that activation of antiviral immune response via TLR4 and CD14 is important in the pathogenesis of viral infection. ${ }^{9}$ A TLR4-deficient mouse model has shown that inflammatory cells did not produce any detectable levels of proinflammatory cytokines in response to LPS. ${ }^{22}$ Fairweather et $a l^{23}$ have reported that TLR4 influenced coxsackievirus replication in mouse model with CVB3induced myocarditis. This model has also shown that TLR4-deficent mice had significantly reduced levels of myocarditis, viral replication and inflammatory cytokine levels. ${ }^{23}$ Our previous study has shown that increased expression of TLR4 is associated with EV replication in human myocarditis. ${ }^{24}$ These reports suggest that activation of TLR4 may play an important role in host immune response against viral infection. In the present study, high levels of TLR4 mRNA expression were seen in DCM patients positive for both plus- and minus-strand EV RNA. A positive correlation was also found between TLR4 mRNA and levels of each strand type of EV RNA. TLR4 immunostaining was found in VP1positive myocytes obtained from DCM patients. In agreement with these findings, Frantz et $a l^{25}$ have reported that TLR4 was abundantly expressed in dysfunctional cardiac myocytes in failing human hearts. However, the trigger for toll expression in failing heart was not clearly identified in Frantz's report. The present study has shown that EV replication may produce both viral protein and RNA in the heart. A mouse model of TLR4 expression has demonstrated that viral protein was an important factor for TLR4 activation during the immune response to a viral pathogen (respiratory syncytial virus) and that TLR4 was an important contributor to the immune response against viral replication. ${ }^{26}$ It is therefore likely that activation of antiviral immune response via TLR4 is triggered by EV replication, and is important in the pathogenesis of DCM.

Another important finding of this study was high levels of both TLR4 mRNA and EV RNA with advanced LV dysfunction in DCM. An EV genometransgenic mouse model has demonstrated that the presence of both strands of EV RNA may activate an intracellular signaling mechanism such as the NF- $\kappa$ B signaling pathway. ${ }^{17}$ TLR4 activates a host immune response that is critical for upregulating the synthesis of a variety of inflammatory mediators and endogenous proteins, such as chemokines, celladhesion molecules, proinflammatory cytokines, inducible nitric oxide synthase (iNOS) and heatshock proteins. ${ }^{8,27,28}$ Our previous studies have demonstrated that TNF- $\alpha$ cascade is activated in human DCM via expression of its converting enzyme and iNOS and that this activation may be related to the clinical severity of DCM. ${ }^{5,6,29}$ Although this study could not confirm a direct causal relationship between activation of the TLR4-signaling pathway and LV dysfunction induced by inflammatory mediators, the LPS-challenged mouse model has demonstrated that TLR4 is tightly linked with NF- $\kappa$ B activation and expression of proinflammatory cytokines such as interleukin 1 and TNF- $\alpha$ in the heart. ${ }^{30}$ These inflammatory mediators have been shown in various reports to produce LV dysfunction..$^{5,6,29,31,32}$ Nemoto et $a l^{33}$ have recently reported that LPS challenge resulted in depression of LV systolic function in wild-type mice, whereas no significant changes in LV systolic function were noted in TLR4-deficient mice. The activated TLR4signaling pathway in the heart may therefore be linked to inflammatory mediators (eg proinflammatory cytokines and iNOS) and to cardiac dysfunction. These observations suggest that activation of the toll-signaling pathway via EV replication may mediate inflammatory mediators and may induce LV dysfunction in human DCM. Therefore, TLR4mediated-immune response to EV replication may allow new approach for treatment of human DCM.

In conclusion, the present study has demonstrated TLR4 expression with the detection of EV RNA and EV protein suggesting the activation of the toll signaling pathway via EV replication in human DCM. In addition, EV RNA and TLR4 mRNA levels may be related to the clinical severity of DCM. The activation of the toll signaling pathway against EV replication may therefore be involved in the pathogenesis of DCM. 


\section{Acknowledgement}

This work was supported by a Grant-in-Aid for General Scientific Research from the Japanese Ministry of Education, Science, Sports and Culture (No. 12770348).

\section{References}

1 Bowles NE, Richardson PJ, Olsen, et al. Detection of coxsackie-B-virus-specific RNA sequence in myocardial biopsy samples from patients with myocarditis and dilated cardiomyopathy. Lancet 1986;1: 1120-1122.

2 Satoh M, Tamura G, Segawa I. Enteroviral RNA in endomyocardial biopsy tissues of myocarditis and dilated cardiomyopathy. Pathol Int 1994;44:345-351.

3 Why HJ, Meany BT, Richardson PJ, et al. Clinical and prognostic significance of detection of enteroviral RNA in the myocardium of patients with myocarditis or dilated cardiomyopathy. Circulation 1994;89: 2582-2589.

4 Fujioka S, Kitaura Y, Ukimura A, et al. Evaluation of viral infection in the myocardium of patients with idiopathic dilated cardiomyopathy. J Am Coll Cardiol 2000;36:1920-1926.

5 Satoh M, Tamura G, Segawa I, et al. Expression of cytokine genes and presence of enteroviral genomic RNA in endomyocardial biopsy tissues of myocarditis and dilated cardiomyopathy. Virchow Arch 1996;427: 503-509.

6 Satoh M, Nakamura M, Saitoh H, et al. Tumor necrosis factor- $\alpha$-converting enzyme and tumor necrosis factor- $\alpha$ in human dilated cardiomyopathy. Circulation 1999; 99:3260-3265.

7 Medzhitov R. Toll-like receptors and innate immunity. Nat Rev Immunol 2001;1:135-145.

8 Medzhitov R, Preston-Hurlburt P, Janeway Jr CA. A human homologue of the Drosophila toll protein signals activation of adaptive immunity. Nature 1997; 388:394-397.

9 Kurt-Jones E, Popova L, Kwinn L, et al. Pattern recognition receptors TLR4 and CD14 mediate response to respiratory syncytial virus. Nat Immunol 2000;5:398-401.

10 Bradenberg RO, Chazov E, Cherian G. Report of the WHO/ISFC task force on the definition and classification of cardiomyopathies. Circulation 1980;64: 1397-1399.

11 Chomczynski P, Sacchi N. Single-step method of RNA isolation by acid guanidinium thiocyanate-phenolchloroform extraction. Anal Biochem 1987;162: 156-159.

12 Zhang HY, Yousef GE, Cunningham L, et al. Attenuation of a reactivated cardiovirulent coxsackievirus B3: The $5^{\prime}$-nontranslated region does not contain major attenuation determinants. J Med Virol 1993;41: 129-137.

13 Klingel K, Rieger P, Mall G, et al. Visualization of enteroviral replication in myocardial tissue by ultrastructural in situ hybridization: identification of target cells and cytopathic effects. Lab Invest 1998;78: 1227-1237.

14 Tam PE, Messner RP. Molecular mechanisms of coxsackievirus persistence in chronic inflammatory myopathy: viral RNA persists through formation of a double-stranded complex without associated genomic mutations or evolution. J Virol 1999;73: 10113-10121.

15 Cunningham L, Bowles NE, Lane RJM, et al. Persistence of enteroviral RNA in chronic fatigue syndrome is associated with the abnormal production of equal amounts of positive and negative strands of enteroviral RNA. J Gen Virol 1990;71:1399-1402.

16 Wessely R, Henke A, Zell R, et al. Low-level expression of a mutant coxsackieviral cDNA induces a myocytopathic effect in culture: an approach to the study of enteroviral persistence in cardiac myocytes. Circulation 1998;98:450-457.

17 Wessely R, Klingel K, Santana LF, et al. Transgenic expression of replication-restricted enteroviral genomes in heart muscle induces defective excitationcontraction coupling and dilated cardiomyopathy. J Clin Invest 1998b;102:1444-1453.

$18 \mathrm{Li} \mathrm{Y,} \mathrm{Bourlet} \mathrm{T,} \mathrm{Andreoletti} \mathrm{L,} \mathrm{et} \mathrm{al.} \mathrm{Enteroviral} \mathrm{capsid}$ protein VP1 is present in myocardial tissues from some patients with myocarditis or dilated cardiomyopathy. Circulation 2000;101:231-234.

19 Heine H, Kirschning CJ, Lien E, et al. Cutting edge: cells that carry A null allele for toll-like receptor 2 are capable of responding to endotoxin. J Immunol 1999;162:6971-6975.

20 Kirschning CJ, Wesche $\mathrm{H}$, Merrill Ayres $\mathrm{T}$, et al. Human toll-like receptor 2 confers responsiveness to bacterial lipopolysaccharide. J Exp Med 1998;188: 2091-2097.

21 Yang RB, Mark MR, Gray A, et al. Toll-like receptor-2 mediates lipopolysaccharide-induced cellular signalling. Nature 1998;395:284-288.

22 Hoshino K, Takeuchi O, Kawai T, et al. Cutting edge: toll-like receptor 4 (TLR4)-deficient mice are hyporesponsive to lipopolysaccharide: evidence for TLR4 as the Lps gene product. J Immunol 1999; 162:3749-3752.

23 Fairweather D, Yusung S, Frisancho S, et al. IL-12 receptor beta1 and toll-like receptor 4 increase IL-1beta- and IL-18-associated myocarditis and coxsackievirus replication. J Immunol 2003;170: 4731-4737.

24 Satoh M, Nakamura M, Akatsu T, et al. Expression of toll-like receptor 4 is associated with enteroviral replication in human myocarditis. Clin Sci (Lond) 2003;104:577-584.

25 Frantz S, Kobzik L, Kim YD, et al. Toll4 (TLR4) expression in cardiac myocytes in normal and failing myocardium. J Clin Invest 1999;104:271-280.

26 Haynes LM, Moore DD, Kurt-Jones EA, et al. Involvement of toll-like receptor 4 in innate immunity to respiratory syncytial virus. J Virol 2001;75: 10730-10737.

27 Brightbill HD, Libraty DH, Krutzik SR, et al. Host defense mechanisms triggered by microbial lipoproteins through Toll-like receptors. Science 1999;188: 2091-2097.

28 Dybdahl B, Wahba A, Lien E, et al. Inflammatory response after open heart surgery: release of heat-shock protein 70 and signaling through toll-like receptor-4. Circulation 2002;105:685-690.

29 Satoh M, Nakamura M, Tamura G, et al. Inducible nitric oxide synthase and tumor necrosis factor-alpha in myocardium in human dilated cardiomyopathy. J Am Coll Cardiol 1997;29:716-724. 
30 Baumgarten G, Knuefermann P, Nozaki N, et al. In vivo expression of proinflammatory mediators in the adult heart after endotoxin administration: the role of toll-like receptor-4. J Infect Dis 2001; 183:1617-1624.

31 Finkel MS, Oddis CV, Jacob TD, et al. Negative inotropic effects of cytokines on the heart mediated by nitric oxide. Science 1992;257:387-389.
32 Yokoyama T, Vaca L, Rossen RD, et al. Cellular basis for the negative inotropic effects of tumor necrosis factor-á in the adult mammalian heart. J Clin Invest 1993;92:2303-2312.

33 Nemoto S, Vallejo JG, Knuefermann P, et al. Escherichia coli LPS-induced LV dysfunction: role of toll-like receptor-4 in the adult heart. Am J Physiol Heart Circ Physiol 2002;282:H2316-H2323. 